\title{
Serial measurements of soluble interleukin 2 receptor levels (sIL2-R) in children with juvenile rheumatoid arthritis treated with oral methotrexate
}

\author{
Carlos D Rose, Paul T Fawcett, Kathy Gibney, Robert A Doughty, Bernhard H Singsen
}

\author{
Division of \\ Rheumatology, \\ Department of \\ Pediatrics, Jefferson \\ Medical College, \\ Philadelphia, PA, USA \\ C D Rose \\ P T Fawcett \\ $R$ A Doughty \\ B H Singsen \\ Department of \\ Research, Division of \\ Immunology, Alfred I \\ duPont Institute, \\ Wilmington, \\ Delaware, USA \\ K Gibney \\ Correspondence to: \\ Dr Carlos Rose, \\ Dr Carlos Rose,
Division of Rheumatology, \\ Division of Rheumatology, \\ Department of Pediatrics,
Alfred I duPont Institute, \\ 1600 Rockland Rd, \\ 1600 Rockland Rd, \\ Wilming. \\ Accepted for publication \\ 27 April 1994
}

\begin{abstract}
Objective-To investigate the potential clinical utility of serial levels of sIL2-R as a marker of disease activity among children with juvenile rheumatoid arthritis (JRA) treated with methotrexate (MTX).

Methods-sIL2-R levels, measured by ELISA, were evaluated in 16 JRA patients (10 polyarticular, six systemic-onset) treated with oral, weekly MTX. SIL2-R values were compared with those of 49 normal controls. Medical record review was used to obtain relevant clinical data. Joint counts (number of swollen joints) were used as indicators of clinical change. A reduction of $50 \%$ in joint counts between pre and post treatment measurements was considered a clinically significant response.

Results-The mean(SEM) sIL2-R value of pre treatment JRA of $1728(290) \mathrm{U} / \mathrm{ml}$ was significantly higher than the post treatment value of $921(229) \mathrm{U} / \mathrm{ml}$ (Wilcoxon Rank test, $p \leqslant 0.001$ ). Pre treatment values were also significantly different from the mean(SEM) of healthy controls of 519(19) $\mathrm{U} / \mathrm{ml}(\mathrm{p}<0.001)$. Pre treatment sIL2-R levels of 2417(291) U/ml in systemic-onset JRA were significantly higher than sIL2- $R$ values in polyarticular JRA patients of 1218(884) U/ml (MannWhitney rank test $p<0 \cdot 001)$. Among the 13/16 children with good therapeutic responses $(\geqslant 50 \%$ improved), the range of sIL2-R decreases was 154-2641 U/ml (mean $842 \mathrm{U} / \mathrm{ml}$ ); sIL2-R levels increased in the three children with poor clinical responses to methotrexate.

Conclusions-sIL2-R levels paralleled the course of disease in all patients. sIL2-R levels may be useful for monitoring therapeutic responses in children with JRA.
\end{abstract}

(Ann Rheum Dis 1994; 53: 471-474)

Soluble interleukin-2 receptor (sIL-2R) is a $45-k d$ protein which is released from white cells after either antigenic activation or mitogenic stimulation. While no definite functional role has yet been established for sIL$2 R$, it is a useful and reliable measure of in vitro and in vivo immune activation in both normal and pathological states. Recent reports suggest that serum levels of sIL-2R correlate with disease activity in adults with various rheumatic disorders, including rheumatoid arthritis (RA), scleroderma and polymyositis. ${ }^{1-6}$ While clinical assessment remains the most reliable means for evaluating disease activity in juvenile rheumatoid arthritis (JRA), a laboratory marker to monitor therapeutic responses would be of value.

Serial measurements of sIL-2R showed correlation with disease activity in 72 adults with RA prospectively investigated over a 24 month period. ${ }^{7}$ In another prospective study of 22 adults over a 12 month period, Rubin et al showed that significant changes in RA disease activity were paralleled by changes in sIL-2R levels only when a significant variation in disease activity was operationally defined as $\geqslant 30 \%$ change. ${ }^{4}$ More recently, the influence of methotrexate treatment on sIL-2R levels was explored in 144 adults with refractory RA enrolled in a Cooperating Rheumatic Diseases Clinics Study. ${ }^{8}$ Their results suggested poor correlation between sIL-2R levels and response to theapy.

In a 1988 cross-sectional study of sIL-2R levels in systemic, poly- and pauci-articular JRA, increased values were found in comparison with controls. ${ }^{9}$ The highest sIL-2R levels corresponded to the first six months of illness, and were inversely related to disease duration. However, correlations with disease activity and treatment responses were not reported. In a recent investigation of 72 children, Silverman et al showed that, within each JRA sub-type, sIL-2R levels correlated better with disease activity than any other test, such as haemoglobin, platelet count, serum albumin, or erythrocyte sedimentation rate. ${ }^{10}$ However, changes in sIL-2R levels over time have not been reported for children with JRA.

We have evaluated serial sIL-2R levels in 16 children with JRA before they received methotrexate, and again after a minimum of three months of treatment. Forty nine normal children served as controls.

\section{Patients and methods}

PATIENTS

Sixty seven children with juvenile rheumatoid arthritis, followed at a paediatric rheumatology 
clinic, have been or currently are receiving oral methotrexate (MTX). All patients fulfilled the American College of Rheumatology diagnostic criteria for JRA. ${ }^{11}$ Of these 67 patients, 54 had received $M T X$ for $\geqslant 3$ months at the time of study inception. Sixteen of the 54 subjects had both pre treatment, and intra treatment stored serum samples available in sufficient amount for sIL-2R testing. The availability of sera in these patients was unrelated to their disease severity, but rather to the fact that our immunology serum bank has been storing all remnant sera from rheumatic patients. These 16 patients, constitute the study group.

\section{CONTROLS}

Sera from 49 non age matched children scheduled to have elective surgery, and enrolled in an autologous blood donor programme, were used as normal controls.

\section{sIL-2R LEVELS}

For baseline, a sample from the time of initiation of MTX therapy was used. For follow up, a sample after at least three months of therapy (see table for interval) was used. Cell free assays for sIL-2R were obtained from $T$ Cell Sciences Inc (Cambridge, MA). All sera were stored at $-70^{\circ}$ until assayed; sIL-2R values have been shown to be stable at $-70^{\circ}$ for at least seven months. ${ }^{1}$ Briefly, 50 microlitres of serum were placed in polystyrene wells which had been pre coated with anti-IL-2R Mab. Peroxidase conjugated, mouse antihuman IL-2R Mab (directed against a different epitope of the sIL-2R molecule) was added immediately after, and incubated for three hours. Wells were then washed with phosphate buffered saline, and colour was developed with O-phenylenediamine. After stopping the reaction with $2 \mathrm{~N} \mathrm{H}_{2} \mathrm{SO}_{4}$, OD values were read at $490 \mathrm{~nm}$ with a Titertek Multi-scan (Flow).

CLINICAL ASSESSMENT

Disease activity was ascertained by medical record review. Response to therapy was assessed by joint counts. Each joint exhibiting

Soluble IL-2R levels and joint counts in 16 children with juvenile rheumatoid arthritis treated with methotrexate

\begin{tabular}{|c|c|c|c|c|c|}
\hline $\begin{array}{l}\text { Patient } \\
\text { number }\end{array}$ & $\begin{array}{l}\text { Sex/age } \\
\text { (onset) }\end{array}$ & $\begin{array}{l}\text { Onset } \\
\text { type } \\
(\star)\end{array}$ & $\begin{array}{l}\text { sIL-2R } \\
(\text { pre/post) } \dagger \\
(U / m l)\end{array}$ & $\begin{array}{l}\text { Foint counts } \\
\text { (pre/post) } \dagger\end{array}$ & $\begin{array}{l}\text { Interval } \\
\text { (months) } \\
\text { (pre/post) } \dagger\end{array}$ \\
\hline 1 & F 4 & $\mathbf{P}$ & $2433 / 358$ & $29 / 3$ & 22 \\
\hline 2 & F 3 & P & $430 / 530$ & $32 / 30$ & 19 \\
\hline 3 & F 7 & P & $798 / 584$ & $29 / 5$ & 22 \\
\hline 4 & M 3 & P & $649 / 406$ & $36 / 0$ & 21 \\
\hline 5 & F 9 & $\mathrm{P}$ & $1477 / 618$ & $30 / 7$ & 20 \\
\hline 6 & F 10 & P & $1043 / 849$ & $15 / 17$ & 24 \\
\hline 7 & F 14 & P & $3128 / 804$ & $42 / 19$ & 17 \\
\hline 8 & F 11 & $\mathbf{P}$ & $782 / 485$ & $36 / 16$ & 3 \\
\hline 9 & F 12 & P & $657 / 404$ & $13 / 4$ & 6 \\
\hline 10 & F 13 & $\mathrm{P}$ & $784 / 513$ & $35 / 16$ & 21 \\
\hline 11 & M 11 & $S$ & $1894 / 996$ & $15 / 8$ & 7 \\
\hline 12 & F 6 & $\mathrm{~s}$ & $910 / 1053$ & $27 / 28$ & 25 \\
\hline 13 & $F_{1}$ & $S$ & $3600 / 918$ & $22 / 10$ & 12 \\
\hline 14 & M 2 & $S$ & $2084 / 3600$ & $43 / 43$ & 17 \\
\hline 15 & F 10 & $S$ & $3393 / 752$ & $31 / 11$ & 15 \\
\hline 16 & F 3 & $S$ & $3600 / 2670$ & $11 / 4$ & 7 \\
\hline
\end{tabular}

$\star P=$ polyarticular; $S=$ systemic onset; + Pre $=$ MTX starting time; Post $=$ follow up evaluation time. swelling (with or without redness, heat or tenderness) due to effusion or synovial thickening was counted as one. Each pre treatment measure was derived by averaging the findings from the two immediately prior to clinic visits, and the one on the date of initiation of methotrexate. The same averaging of three clinic visits was done at the final methotrexate treatment evaluation, starting with the visit corresponding to the available follow up sample, and then followed by the two subsequent visit records. Visits occurred at intervals of three to six weeks. The requirement of a three month minimum between evaluations was felt necessary to allow the 'responders' to have experienced clinical response. The latter was a priori defined as $\geqslant 50 \%$ reduction in joint count. Rubin et al required $a \geqslant 30 \%$ reduction of clinical values. ${ }^{4}$ We felt that $a \geqslant 50 \%$ reduction was more likely to reflect clinical relevance in a retrospective study.

STATISTICAL ANALYSIS

Mann-Whitney rank sum test was used to compare mean sIL-2R levels among the two sub-sets of JRA, and JRA with controls, and the Wilcoxon signed rank test was used to compare mean sIL-2R levels at pre and post methotrexate treatment times.

\section{Results}

The study group included 13 females and three males. The ages at starting MTX were three to 18 years (mean: 10.5 years). The table shows age at disease onset. There were 10 with polyarticular onset and six with systemic onset JRA. All had polyarthritis when treatment was started, and five of six systemic-onset children had fever and/or rash when treatment was initiated; two or these latter (numbers 12 and 14) had persistent systemic findings at follow up evaluation. Disease duration at initiation of MTX ranged from three to 228 months (mean: 53.8 months). Three patients had a positive ANA, and one was rheumatoid factor positive. Eight children were receiving ibuprofen, six were taking tolmetin sodium, and one each was receiving naproxen sodium and indomethacin. Due to the refractory nature of their JRA, six of the 16 children were also receiving oral prednisone at varying doses during the evaluation period. At the time of final assessment, prednisone doses were $0.75,2.5$, $2 \cdot 5,5.0,7 \cdot 5$, and $10.0 \mathrm{mg} /$ day (alternate day regimes were averaged to a daily dose).

Mean(SEM) sIL-2R values of pre treatment JRA [1728(290) U/ml] and intratreatment JRA [921(229) U/ml] were significantly different compared with controls [519(19) U/ml] $(p<0.001)$. Mean(SEM) serum levels of sIL$2 \mathrm{R}$ were higher among systemic-onset JRA patients [2417(291) U/ml] compared with polyarticular-onset patients [1218(884) $\mathrm{U} / \mathrm{ml}]$. This difference was statistically significant $(p<0.001)$. See table for individual values.

Among the 12 children who had $\geqslant 50 \%$ reductions in joint counts (for example, a 
significant clinical response to methotrexate), and patient 11 who had a $46 \%$ reduction in his joint count, the range of decreases of sIL-2R levels was 154-2641 U/ml (mean $842 \mathrm{U} / \mathrm{ml}$ ). In contrast, there were absolute increases in serum levels of sIL-2R (range of increase: 100-1516 U/ml; mean $586 \mathrm{U} / \mathrm{ml}$ ) among the three other children.

\section{Discussion}

Elevated serum levels of sIL-2R, while not disease specific, may be a sensitive marker for immune activation. ${ }^{2}$ As a marker of disease activity, serum and synovial fluid levels of sIL$2 \mathrm{R}$ have been investigated in rheumatoid arthritis, psoriatic arthritis, scleroderma, polymyositis, systemic lupus erythematosus, Kawasaki disease, and Wegener's granulomatosis. ${ }^{13-6}$ 12-18 Generally, sIL-2R levels are elevated with increased disease activity in these disorders and are more sensitive than the ESR in both RA and SLE. ${ }^{1}$ The value of sIL-2R levels as a sensitive indicator of responsiveness of adult rheumatoid arthritis to immunosuppressive therapy with both cyclosporine $\mathrm{A}$, and azathioprine, ${ }^{12}$ and of psoriatic arthritis to cyclosporine $\mathrm{A},{ }^{16}$ has also been suggested.

Significant correlations between sIL-2R levels and both joint counts and increasing levels of disease activity have been shown for JRA, ${ }^{10}$ but relationships with treatment responses have not been evaluated. Our study was designed to: 1) extend the few observations of the relationship between sIL-2R levels and disease activity in JRA, and 2) assess the value of monitoring sIL-2R levels in JRA to measure change in disease activity due to a therapeutic intervention (for example, methotrexate).

The present investigation suggests that, overall, mean sIL-2R levels are significantly higher in patients with JRA in comparison with controls; these findings are similar to those of previous studies. ${ }^{1410}$ In our population, sIL$2 \mathrm{R}$ values were twice as high among the systemic group as among children with polyarticular JRA. Silverman et $a l^{10}$ described findings similar to ours, while Barron et al reported little difference in sIL-2R values between the systemic and polyarticular onset groups. ${ }^{9}$ It has been suggested that synovial lymphocytes are the main source of sIL-2R in patients with synovitis. However, the higher levels of sIL-2R in systemic-onset JRA, who in our study exhibited joint counts similar to polyarticular-onset JRA, suggests that systemic-onset patients may have extraarticular sources as well. In the study by Silverman et al it was shown that the degree of JRA disease activity correlated better with sIL$2 \mathrm{R}$ levels in all onset sub-types than with any other laboratory test. ${ }^{10}$ Furthermore, three of their four patients with serial determinations of sIL-2R showed levels paralleling the course of the JRA, with a fall in serum values when clinically active disease became quiescent. ${ }^{10}$ In our investigation, that correlation is confirmed by the changes in sIL-2R levels in children who appear to respond to MTX. It is conceivable that the decrease in sIL-2R levels in responders occurs as a result of a reduction in the size or degree of activation of the sIL-2R releasing cell population. The amount of sIL-2R level reduction was relatively small in our study, with only four patients showing $>50 \%$ decreases. When combined with the lack of information on physiological variability of sIL$2 \mathrm{R}$ levels in children, this suggests that our data should be interpreted with caution.

sIL-2R levels for paediatric controls in the two other JRA series were similar to ours. Mean levels of sIL-2R in our study population, before MTX treatment, were similar to those in patients with active JRA described by Silverman et al $(1728 \mathrm{U} / \mathrm{ml} v 1745 \mathrm{U} / \mathrm{ml}) .^{10}$ Our group treated with methotrexate also showed comparable sIL-2R levels to the children with 'inactive JRA' from Silverman et al $(846 \mathrm{U} / \mathrm{ml} v 989 \mathrm{U} / \mathrm{ml})$. These findings suggest good reproducibility of this ELISA test in both normal and rheumatic children. ${ }^{9} 10$

In summary, our findings suggest that sIL$2 \mathrm{R}$ levels in children with active JRA, particularly those with systemic onset, are higher than in controls. These levels appear to parallel the evolution of disease activity in those JRA children receiving weekly oral methotrexate therapy. A prospective study is underway to investigate the value of measuring sIL-2R levels to predict response to MTX, and other therapies, in juvenile rheumatoid arthritis and related disorders.

1 Campen D H, Horwitz D A, Quismorio F P Jr, Ehresmann G R, Martin W J. Serum levels of interleukin-2 receptor and activity of rheumatic diseases characterized by immune system activation. Arthritis Rheum 1988; 31: immune

2 Rubin L A. The soluble interleukin-2 receptor in rheumatic disease. Arthritis Rheum 1990; 33: 1145-48.

3 Clements P J, Peter J B, Agopian M S, Telian N S, Furs $D$ E. Elevated serum levels of soluble interleukin 2 receptor, interleukin 2 and neopterin in diffuse and limited scleroderma: Effect of chlorambucil. $\mathcal{f}$ Rheumatol 1990; 17: 908-10.

4 Rubin L A, Snow K M, Kurman C C, Nelson D L, Keystone E C. Serial levels of soluble interleukin 2 receptor in the peripheral blood of patients with rheumatoid arthritis: Correlation with disease activity. $\mathcal{f}$ Rheumatol 1990; 17: 597-602.

5 Wolf R E, Baethge B A. Interleukin 1-a, Interleukin-2 and soluble interleukin-2 receptors in polymyositis. Arthritis Soluble interleukin-2 recep.

6 Schmitt W H, Heesen C, Csernok E, Rautmann A, Gross W L. Elevated serum levels of soluble interleukin-2 receptor in patients with Wegener's granulomatosis: Evidence of T-cell activation. Arthritis Rheum 1992; 35: 1088-96.

7 Keystone E C, Know K M, Bomardier C, et al. Elevated soluble IL-2 receptor levels in the sera and synovial fluids of patients with rheumatoid arthritis. Arthritis Rheum 1988; 31: 844-9.

8 Dooley M A, Pisetsky D S, Dawson D V, Polisson R P. Soluble serum IL-2 receptor levels in refractory RA: trends during MTX therapy. Arthritis Rheum 1991; 34: S36.

9 Barron K S, Montalvo J F, Saadeh C K, Orson F M. Soluble interleukin-2 receptors (IL-2R) in children with juvenile rheumatoid arthritis (JRA). Arthritis Rheum 1988; 31: S78.

10 Silverman E D, Laxer R M, Nelson D L, Rubin L A. Soluble Interleukin-2 receptor in juvenile rheumatoid arthritis. $\mathcal{f}$ Rheumatol 1991; 18: 1398-402.

11 Brewer E J, Bass J, Baum J, et al. Current proposed revision of JRA criteria. Arthritis Rheum 1977; 20(suppl): 195-9.

12 Corvetta A, Luchetti M M, Pomponio G, et al. Interleukin 2 , soluble interleukin-2 receptor and tumor necrosis factor in sera from patients with rheumatoid arthritis. Res Clin Lab 1990; 20: 275-81.

13 Vaisberg M, Scheinberg M A. Simultaneous evaluation of membrane bound and soluble interleukin-2 receptor expression in the blood and synovial fluid of patients with rheumatoid arthritis. Clin Exp Rheumatol 1990; 8: 579-82.

14 Zielinski C C, Pesau B, Muller C. Soluble interleukin-2 receptor and soluble CD8 antigen in active rheumatoid 
arthritis. Clin Immunol Immunopathol 1990; 57: 74-82.

15 Miossec P, Elhamiani M, Chichehian B, et al. Interleukin-2 (IL-2) in rheumatoid synovial fluid: Correlation with prognosis and soluble IL-2 receptor levels. $\mathcal{f}$ Clin Immunol 1990; 10: 115-20.

16 Salvarani C, Macchioni P, Boiardi L, et al. Low dose cyclosporine A in psoriatic arthritis: Relation between soluble interleukin 2 receptors and response to therapy. f Rheumatol 1992; 19: 74-9.
17 Raziuddin S, Al-Janadi M A, Al-Wabel A A. Soluble Interleukin 2 receptor levels in serum and its relationship to $T$ cell abnormality and clinical manifestations of the disease in systemic lupus erythematosus. $f$ Rheumatol 1991; 18: 831-6.

18 Barron K S, Montalvo J F, Saadeh C K, et al. The usefulness of measuring soluble interleukin-2 receptor levels in children with Kawasaki syndrome. Arthritis Rheum 1988; 31: S77. 